\title{
Pengaruh Harga Rokok terhadap Perilaku Konsumsi Rokok pada Mahasiswa di Jatinangor
}

\author{
Bayu Rizky Prasetyo*1, Estro Dariatno Sihaloho \\ Departemen Ilmu Ekonomi Fakultas Ekonomi dan Bisnis Universitas Padjadjaran \\ *correspondence email: bayurizkyp@gmail.com
}

\begin{abstract}
Abstrak. Indonesia menanggung beban yang besar atas masalah kesehatan yang timbul atas konsumsi rokok. Banyak kebijakan yang dilakukan pemerintah agar dapat mengontrol konsumsi rokok secara nasional. Salah satunya adalah dengan meningkatkan harga rokok. Penelitian ini dilakukan untuk mengetahui mengenai pengaruh harga rokok dengan pendapatan uang saku mahasiswa terhadap konsusmsi rokok. Metode penelitian yang digunakan dalam penelitian ini adalah regresi linier berganda. Data yang digunakan pada penelitian ini merupakan data primer yang didapatkan menggunakan survey di Jatinangor. Teknik Pengambilan Data yang dilakukan pada penelitian ini merupakan random sampling, dengan jumlah responden sebanyak 60 orang mahasiswa. Data Karakteristik responden dalam penelitian ini meliputi Harga Rokok, Pendapatan Uang Saku bulanan dan jumlah konsumsi rokok per bulan mahasiswa yang tinggal di Jatinangor. Berdasarkan hasil analisis regresi linear berganda diperoleh bahwa harga rokok dan pendapatan uang saku mahasiswa berpengaruh positif dan signifikan terhadap konsumsi rokok. Hasil ini dapat menjadi rekomendasi bagi pemerintah bahwa kenaikan harga rokok tidak dapat mengurangi konsumsi rokok secara signifikan. Pemerintah dapat mengeluarkan larangan merokok yang lebih efektif mengontrol konsumsi rokok pada mahasiswa.
\end{abstract}

Kata kunci: Harga Rokok; Konsumsi Rokok; Mahasiswa

Abstract. Indonesia bears a huge burden on health problems arising from cigarette consumption. Many policies have been made by the government in order to control national cigarette consumption. One way is to increase the price of cigarettes. This research was conducted to determine the effect of cigarette prices with the income of student allowances on cigarette consumption. The research method used in this study is multiple linear regression. The data used in this study are primary data obtained using a survey in Jatinangor. Data collection techniques used in this study were random sampling, with a total of 60 students respondent. Data Characteristics of respondents in this study include cigarette prices, monthly allowance income and the number of cigarette consumption per month of students who live in Jatinangor. Based on the results of multiple linear regression analysis, it is found that the price of cigarettes and student allowance income has a positive and significant effect on cigarette consumption. This result can be a recommendation for the government that an increase in cigarette prices cannot significantly reduce cigarette consumption. The government can issue a smoking ban that is more effective in controlling the consumption of cigarettes to students.

Keywords: Cigarette Prices; Cigarette Consumption; University Students

\section{PENDAHULUAN}

Kemajuan yang terjadi pada era digital saat ini telah membuat banyaknya perubahan dalam dunia bisnis yang semakin berkembang pesat. Di era ini, para konsumen menuntut perusahaan untuk memproduksi barang maupun jasa sesuai dengan selera, kebutuhan, serta daya beli konsumen itu sendiri. Tuntutan ini tentu menyebabkan semakin meningkatnya persaingan antara perusahaan yang satu dengan yang lain yang semakin meningkat demi memenuhi tuntutan dari para konsumen yang semakin kompleks. Dengan semakin meningkatnya persaingan antar perusahaan menyebabkan semakin dibutuhkannya peranan kualitas dari produk yang akan dipasarkan sebagai cerminan dari suatu perusahaan yang memproduksinya. Bagi sebuah perusahaan sangat penting untuk menganalisis perilaku para konsumen yang tentunya akan selalu berkembang dengan cara memahami perilaku dari konsumen itu sendiri, dengan hal tersebut maka akan menentukan jumlah konsumsi barang atau jasa yang akan dibutuhkan oleh konsumen tersebut serta menunjukan pula mengenai produk yang dibutuhkan oleh masyarakat pada saat itu.

Philip \& Keller (2012) mengemukakan bahwa suatu produk yang ditawarkan ke pasar berguna untuk mendapatkan perhatian, selain itu produk yang dijual maupun dibeli, digunakan, maupun dikonsumsi yang tentunya agar dapat memenuhi keinginan maupun kebutuhan konsumen. Teori yang dikemukakan oleh Philip dan Keller ini juga didukung oleh penelitian yang dilakukan oleh Sagarawanti dan Hidayat (Sagarawanti and Hidayat 2015) yang menyatakan bahwa variabel paling dominan mempengaruhi konsumen dalam mengkonsumsi suatu produk.

Rokok merupakan salah satu produk terbesar yang memiliki peminat tinggi dikalangan masyarakat Indonesia (Purwati, Setiawan, \& Rohmawati, 2012). Hal ini menimbulkan beban ekonomi dan kesehatan yang besar untuk Indonesia. Bahkan konsumsi rokok sangat tinggi dikalangan orang miskin di Indonesia (Suryawati, Kartikawulan, and Haryadi 2012). Hal ini menjadikan masyarakat miskin di Indonesia menjadi sulit lepas dari 
jerat kemiskinan. Saat ini pengguna rokok di kalangan mahasiswa juga meningkat (Salawati and Amalia 2010). Merokok sejak usia muda akan mengakibatkan dampak kesehatan yang buruk bagi mahasiwa tersebut. Pemerintah melakukan berbagai upaya untuk mengontrol konsumsi rokok. Salah satunya adalah meningkatkan harga rokok. Penelitian ini ingin menganalisis bagaimana pengaruh harga rokok terhadap konsumsi rokok di kalangan mahasiswa di Jatinangor.

\section{Definisi Harga}

Harga dapat didefinisikan sebagai suatu nilai atau nominal yang ditukarkan oleh konsumen dengan manfaat dari memiliki ataupun pada saat menggunakan produk maupun jasa yang nominalnya telah ditetapkan oleh pembeli maupun penjual melalui proses tawar menawar serta ditetapkan oleh penjual untuk satu harga sepakat antara penjual dan pembeli. Menurut Kotler dan Keller (Philip and Keller 2012) harga harus mencerminkan nilai atau nominal konsumen saat bersedia membayar sebuah produk dibandingkan saat konsumen tersebut harus mencerminkan biaya pembuatan produk maupun memberikan sebuah layanan. Oleh karena itu dapat dikatakan bahwa harga adalah sejumlah uang yang dibutuhkan maupun ditukarkan kepada konsumen dalam rangka mendapatkan atau memiliki suatu barang yang tentunya memiliki manfaat maupun kegunaannya.Menurut Buchari Alma (Buchari 2011) dalam menetapkan harga tentunya melalui keputusan yang tentunya akan diikuti dalam rentang waktu tertentu. Jika harga yang ditetapkan ternyata lebih tinggi daripada nilai yang diterima, maka penjual atau perusaahan yang bersangkutan akan kehilangan kemungkinan untuk memperoleh laba atas penjualannya. Namun jika harga yang ditawarkan terlalu rendah daripada nilai yang diterima, maka besar kemungkinannya penjual atau perusahaan yang bersangkutan akan memperoleh laba atau keuntungan yang besar.

Tjiptono Fandy (Fandy 2008) mengemukakan teori dalam metode penetapan secara garis besar yang dikelompokkan menjadi empat kategori, yaitu sebuah metode penetapan harga berbasis permintaan, metode penetapan harga berbasis biaya, metode penetapan harga berbasis laba serta metode penetapan harga berbasis persaingan. (Lupiyoadi 2001) menyatakan bahwa strategi penentuan harga (pricing) signifikan terhadap pemberian value kepada konsumen dan mempengaruhi image produk serta keputusan konsumen untuk membeli. Sebuah harga adalah indikator atau alat ukur yang digunakan oleh para konsumen dalam menentukan pilihan pembelian apabila harga yang ditawarkan dihubungkan dengan manfaat yang didapat atas barang maupun jasa. Harga juga merupakan sebuah komponen yang memiliki pengaruh terhadap laba atau keuntungan bagi penjual atau bagi perusahaan. Menurut (Fandy 2008) tingkat sebuah harga yang ditetapkan memiliki pengaruh kuantitas yang terjual. Maka dapat disimpulkan bahwa secara tidak langsung sebuah harga memiliki pengaruh terhadap biaya karena hal tersebut kuantitas yang terjual berpengaruh pada biaya yang ditimbulkan yang erat kaitannya dengan efisiensi produksi, sehingga dalam menetapkan harga penjual atau perusahaan sangat memiliki peran penting. Selain faktor diatas, penetapan harga juga dipengaruhi oleh ketetapan pemerintah. Seperti pada rokok, harga rokok dipengaruhi oleh besar cukai yang ditetapkan oleh pemerintah (Suprihanti et al. 2019).

\section{Teori Pendapatan}

Pendapatan atau revenue atau dapat juga disebut sebagai income adalah sejumlah penerimaan berupa upah atau gaji yang berbentuk uang dan berbentuk selain uang yang diterima oleh seseorang atau perusahaan atas hasil penjualan berupa barang maupun jasa yang telah dilakukan. Menurut (Case and Fair 2007) mengemukakan bahwa terdapat tiga bentuk sumber pendapatan atau pemasukan seseorang maupun pendapatan rumah tangga, diantaranya adalah pendapatan yang didapat dari gaji atau upah sebagai bentuk imbalan atas tenaga kerja, pendapatan yang berasal dari hak milik berupa modal, tanah dan lain sebagainya serta pendapatan yang berasal dari pemerintah. Suyanto dan Nurhadi (Suyanto and Nurhadi 2003) mengemukakan sumber-sumber pendapatan rumah tangga menjadi beberapa golongan, yaitu seperti kekayaan, gaji, upah dan bunga. Mahasiwa memperoleh uang saku dari orangtua yang memperoleh pendapatan dari berbagai sumber seperti gaji, upah, sewa maupun penghasilan yang didapat dari usaha, yang kemudian diakumulasi dalam waktu satu bulan penuh. (Sumardi and Evers 1991) mengemukakan cara untuk menghitung pendapatan atau penghasilan dari orang tua yang dapat kita hitung berdasarkan tiga cara yaitu pendapatan formal (tetap), pendapatan informal (tidak tetap), dan pendapatan subsistem.

\section{Teori Konsumsi}

Konsumsi adalah sebuah kegiatan ekonomi dimana ketika seseorang menggunakan serta menghabiskan barang maupun jasa untuk memenuhi segala kebutuhan hidupnya(Miller and Keynes 1972). Dalam kegiatan sehari-hari kita tentu tidak dapat terlepaskan dari kegiatan konsumsi dimana istilah konsumsi tidak hanya dilakukan oleh seseorang individu, namun dapat dikaitkan pula dalam kegiatan rumah tangga. Menurut Keynes, kegiatan konsumsi didorong oleh motivasi yang berasal dari diri sendiri dan bukan dari paksaan orang lain dan konsumsi ini memiliki sifat subjektif, yaitu keinginan individu dalam memenuhi kebutuhannya. Keynes menjelaskan fungsi konsumsi yang didasari oleh asumsi teori yang beliau duga. Berikut adalah fungsi yang dikemukakan oleh Keynes, $\mathbf{C}=\boldsymbol{C o}+\boldsymbol{b} \boldsymbol{Y d}$, dimana $\mathrm{C}$ adalah pengeluaran 
konsumsi itu sendiri, Co adalah besarnya konsumsi pada saat pendapatan tidak ada (konsumsi otonomous), b adalah marginal prospensity to consume yaitu besarnya pertambahan konsumsi saat pendapatan disposabel meningkat, Yd adalah pendapatan (Miller and Keynes 1972).

\section{METODE}

Pengggunaan data yang digunakan dalam penelitian ini ialah metode penelitian yang menggunakan metode kuantitatif dengan pendekatan deskriptif, hal ini dikarenakan data yang akan dijelaskan akan dijabarkan dengan menggunakan angka-angka (Sugiyono 2011). Data yang digunakan pada penelitian ini merupakan data hasil pengamatan langsung oleh penulis dengan melibatkan sebanyak 60 orang responden mahasiswa yang tinggal di Jatinangor. Teknik Pengambilan Data yang dilakukan adalah random sampling dengan melakukan wawancara terhadap 60 orang mahasiswa yang tinggal di Jatinangor. Data Karakteristik responden dalam penelitian ini meliputi Harga Rokok (Variabel Bebas X1), Pendapatan Uang Saku bulanan (Variabe Bebas X2) dan perilaku konsumsi rokok per bulan (Variabel terikat Y) Analisis Data yang digunakan yaitu analisis regresi linier berganda, yaitu teknik analisis statistik untuk menegetahui hubungan linier antara dua atau lebih variabel bebas (X1, X2, dst) terhadap variabel terikat $(\mathrm{Y})$.

\section{HASIL DAN PEMBAHASAN}

Deskripsi statistik pada varibel yang digunakan dalam penelitian ini adalah sebagai berikut :

Tabel 1. Deskripsi Statistik

\begin{tabular}{llllll}
\hline Variabel & Obs & Mean & Std.Dev. & Min & Max \\
\hline Harga Rokok (Rp) & 60 & 16.208 & 3137,109307 & 10.000 & 22.500 \\
Pendapatan Uang Saku (Rp) & 60 & 1206667 & 484546,5001 & 600.000 & 4.000 .000 \\
Perilaku Konsumsi Per Bulan (Bungkus) & 60 & 46 & 19,38951752 & 15 & 90 \\
\hline
\end{tabular}

Sumber data: diolah

Tabel 2. Hasil Regresi

\begin{tabular}{|c|c|c|c|c|c|c|}
\hline Source & SS & $\mathrm{df}$ & MS & Number of obs & $=$ & 60 \\
\hline \multirow{2}{*}{ Model } & \multirow{2}{*}{5411,33} & \multirow{2}{*}{2} & \multirow{2}{*}{27056664} & $\mathrm{~F}(2,57)$ & $=$ & 9,2 \\
\hline & & & & Prob $>F$ & $=$ & 0,0003 \\
\hline \multirow{2}{*}{ Residual } & \multirow{2}{*}{16769,9} & \multirow{2}{*}{57} & \multirow{2}{*}{294209074} & R-squared & $=$ & 0,244 \\
\hline & & & & Adj R-squared & $=$ & 0,2174 \\
\hline Total & 22181.25 & 59 & 375,95339 & Root MSE & $=$ & 17,153 \\
\hline Perilaku Konsumsi & Coef. & Std. Error & $\mathrm{t}$ & $\mathrm{P}>|\mathrm{t}|$ & [95\% Conf. & val] \\
\hline HargaRokokRp & 0,001688 & 0,000753 & 2,24 & 0,029 & 0,001786 & 0,0031 \\
\hline UangSakuRp & 0,000013 & $4,88 \mathrm{E}-06$ & 2,72 & 0,009 & $3,48 \mathrm{E}-06$ & 0,0002 \\
\hline _cons & 2,89083 & 11,89512 & 0,24 & 0,809 & $-20,92872$ & 26,710 \\
\hline
\end{tabular}

Sumber data: diolah

Dari hasil perhitungan $\mathrm{P}-\mathrm{Value}$, variabel $\mathrm{X} 1$ (Harga Rokok) bernilai sebesar 0,029 dan variabel X2 (Pendapatan Uang Saku) bernilai 0,009. Variabel X1 yaitu harga rokok memiliki nilai P-value lebih kecil dari alpha $(0,05)$ dan Variabel $\mathrm{X} 2$ yaitu uang saku memiliki nilai $\mathrm{P}$-value lebih kecil dari alpha $(0,05)$ sehingga disimpulkan bahwa harga rokok dan pendapatan uang saku memiliki pengaruh signifikan terhadap perilaku konsumsi. Koefisien determinasi (R Square) adalah 0,2440 atau $24,40 \%$, dan sisanya sebesar $75,60 \%$ dapat dijelaskan oleh variabel lain yang tidak termasuk dalam penelitian ini. Hasil ini sesuai dengan penelitian sebelumnya yang diteliti oleh Mohammad Maftuh Baedowi ZA, Eisha Lataruva (Baedowi Mohammad Maftuh and Eisha 2012) bahwa Variabel Kesesuaian harga memiliki pengaruh terhadap keputusan pembelian rokok.

\section{Uji t}

Uji t pada dasarnya bertujuan untuk mengetahui apakah variabel bebas memiliki pengaruh yang signifikan terhadap variabel terikat secara sebagian atau parsial. Uji t dilakukan dengan cara membandingkan nilai $t_{\text {hitung }}$ dengan nilai $t_{\text {tabel. }}$. Dengan tingkat signifikansi sebesar $5 \%$ atau 0,05 , apabila nilai $\mathrm{t}$ sig $\leq \alpha$ maka $\mathrm{H} 0$ ditolak, hal ini berarti tidak terdapat pengaruh yang signifikan secara parsial antara variabel bebas (uangsaku, hargarokok) terhadap variabel terikat (consummonth) dalam model. Sebaliknya, apabila nilai t sig > $\alpha$ maka $\mathrm{HO}$ diterima, hal ini berarti terdapat pengaruh yang signifikan secara parsial antara variabel bebas terhadap variabel terikat dalam model.

Asumsi:

$\mathrm{H} 0: \mathrm{b} 1=0$, artinya secara parsial, tidak ada pengaruh positif dan signifikan antara variabel independen terhadap variabel dependen.

Ha : $\mathrm{b} 1 \neq 0$, artinya secara parsial, terdapat pengaruh positif dan signifikan antara variabel independen terhadap variabel dependen.

\section{Kriteria:}

Jika $\mathrm{t}_{\text {sig }}<\alpha$ maka $\mathrm{H}_{0}$ ditolak

Jika $t_{\text {sig }}>\alpha$ maka $\mathrm{H}_{0}$ tidak dapat ditolak 
Bayu Rizky Prasetyo dan Estro Dariatno Sihaloho, Pengaruh Harga Rokok terhadap Perilaku Konsumsi Rokok pada

Dapat diamati dari hasil regresi pada gambar tabel diatas, variabel $\mathrm{X}_{1}$ (harga rokok) memiliki $\mathrm{t}$ hitung sebesar 2,24 dan probabilitas sebesar 0,029. Dan variabel X2 (pendapatan uang saku) memiliki T hitung sebesar 2,72 dan probabilitas sebesar 0,009. Dengan tingkat signifikansi (alpha) 5\%, kedua variabel bebas yaitu variabel harga rokok dan variabel pendapatan uang saku memiliki probabilitas kurang dari alpha maka $\mathrm{H}_{0}$ ditolak. Dapat disimpulkan bahwa kedua variabel bebas dalam model memiliki pengaruh yang signifikan terhadap variabel terikat yaitu perilaku konsumsi rokok per bulan.

\section{Uji F}

Uji F merupakan metode pengujian parsial yang menunjukkan apakah semua variabel independen atau variabel bebas memiliki pengaruh secara bersamaan terhadap variabel dependen atau variabel terikat.

\section{Asumsi $=$}

$\mathrm{H}_{0}: \mathrm{b} 1=\mathrm{b} 2=\mathrm{bn}$, artinya tidak terdapat pengaruh simultan yang signifikan antara variabel independen terhadap variabel dependen.

$\mathrm{Ha}: \mathrm{b} 1 \neq \mathrm{b} 2 \neq \mathrm{bn}$, artinya terdapat pengaruh simultan antara variabel independen terhadap variabel dependen.

Kritetia:

- H0 ditolak, jika nilai $\mathrm{F}$ hitung $>\mathrm{F}$ tabel

- H0 tidak dapat ditolak, jika nilai F hitung < F tabel

Hasil Uji:

Berdasarkan hasil uji probabilitas nilai $\mathrm{F}$ hitung sebesar 9,20 dan F tabel sebesar 2,764. Maka F hitung > $\mathrm{F}$ tabel Ho ditolak. Maka dengan signifikansi 5\% terdapat pengaruh simultan antara variabel independen terhadap variabel dependen.

\section{Uji $R^{2}$}

Koefisien determinasi atau $\mathrm{R}^{2}$ adalah uji yang mencari tahu seberapa besar kemampuan semua variabel independen dapat menjelaskan variabel dependen. Pada hasil regresi, dapat dilihat bahwa $\mathrm{R}^{2}$ sebesar 0,2440 atau $24,40 \%$ maka dapat dikatakan bahwa variabel independen berpengaruh terhadap varibel dependen sebesar $24,40 \%$.

\section{Uji Multikolinearitas}

Multikolinearitas adalah sebuah situasi yang menunjukkan adanya korelasi atau hubungan kuat antara dua variabel bebas atau lebih dalam model regresi linear. Uji Multikolinearitas dilakukan dengan cara melihat nilai VIF.

\begin{tabular}{rrr}
\multicolumn{3}{c}{ Tabel 3. Uji VIF } \\
\hline Variable & VIF & 1/VIF \\
\hline Harga Rokok Rp & 1,12 & 0,891499 \\
Pendapatan Uang Saku Rp & 1,12 & 0,891499 \\
\hline Mean VIF & 1,12 & \\
\hline
\end{tabular}

Hipotesis:

Ho = Tidak terdapat masalah multikolinearitas dalam model

$\mathrm{Ha}=$ Terdapat multikolinearitas dalam model

\section{Kriteria:}

Nilai VIF $>5=$ Ho Ditolak

Nilai VIF $<5=$ Ho Tidak dapat ditolak

Hasil Uji:

Dalam model dapat dilihat bahwa VIF dari kedua variabel independen sebesar 1,12 $<5$ Ho tidak dapat ditolak yang berarti tidak terdapat masalah multikolinearitas dalam model.

\section{Uji Heteroskedastisitas}

Uji Heteroskedastisitas adalah uji yang menilai apakah ada ketidaksamaan varian dari residual untuk semua pengamatan pada model regresi linear. Uji ini merupakan salah satu dari uji asumsi klasik yang harus dilakukan pada regresi linear. Apabila asumsi heteroskedastisitas tidak terpenuhi, maka model regresi dinyatakan tidak valid sebagai alat peramalan.

\section{Hipotesis:}

Ho =Tidak terdapat masalah Heteroskedastisitas atau error term bersifat Homoskedastik

$\mathrm{Ha}=$ Terdapat masalah Heteroskedastisitas atau error term bersifat Heteroskedastik

Tabel 4. Uji Breusch-Pagan

Breusch-Pagan / Cook-Weisberg test for heteroskedasticity Ho :Constant variance

Variables: fitted values of hargarokok

$\operatorname{chi} 2(1)=0,63$

Prob $>\operatorname{ch} 2=0,4283$

Kriteria:

$\mathrm{LM}>\chi_{k}^{2}$ atau P-Value $<\alpha=$ Ho Ditolak

$\mathrm{LM}<\chi_{k}^{2}$ atau P-Value $>\alpha=$ Ho Tidak dapat ditolak

Hasil Uji:

Dalam model dapat dilihat bahwa P-value sebesar $0,4283>0,05$. Nilai P-Value $>\alpha$ Ho tidak dapat ditolak. Maka dengan tingkat signifikansi 5\% tidak terdapat masalah Heteroskedastisitas atau error term bersifat Homoskedastik. 


\section{SIMPULAN}

Penelitian ini menunjukkan bahwa peningkatan harga tidak mengurangi konsumsi rokok pada mahasiswa di Jatinangor. Bahkan dengan pengaruh faktor lainnya, konsumsi rokok mahasiswa bahkan mengalami kenaikan. Hasil regresi pada penelitian ini menunjukkan bahwa harga rokok dan jumlah uang saku berpengaruh positif dan signifikan pada konsumsi rokok mahasiswa. Pemerintah dapat memperketat peraturan mengenai rokok jika ingin mengontrol konsumsi rokok di kalangan mahasiswa di Jatinangor atau seluruh Indonesia. Kebijakan kampus yang melarang mahasiswa merokok di lingkungan kampus adalah hal tepat untuk mengurangi konsumsi rokok dikalangan mahasiswa.

\section{DAFTAR PUSTAKA}

Baedowi Mohammad Maftuh, and Lataruva Eisha. 2012. "Analisis Pengaruh Kualitas Produk, Kesesuaian Harga Dan Intensitas Promosi Terhadap Keputusan Pembelian Konsumen Pada Merek Rokok Djarum Super" 1: 1-8.

Buchari, Alma. 2011. Manajemen Pemasaran Dan Pemasaran Jasa. Bandung: Alfabeta.

Case, Karl E., and Ray. C Fair. 2007. Prinsip-Prinsip Ekonomi. 8th ed. Jakarta.

Fandy, Tjiptono. 2008. Strategi Bisnis Pemasaran. Yogyakarta: Andi.

Lupiyoadi, Rambat. 2001. Manajemen Pemasaran Jasa: Teori Dan Praktik. Jakarta.

Miller, Tim, and Explaining Keynes. 1972. "Explaining Keynes ' Theory of Consumption, and Assessing Its Strengths and Weaknesses ." Review of Social Economy.

https://doi.org/10.1080/00346760601024443.

Philip, Kotler, and Kevin Lane Keller. 2012. Marketing Management. 14th ed. New Jersey: Prentice.

Purwati, Setiawan, and Rohmawati. 2012. "Pengaruh Harga Rokok Dan Kualitas Produk Terhadap Keputusan Pembelian Motor Honda Matic Beat (Studi Kasus Pada PT. Nusantara Solar Sakti)." Ekonomi Dan Informasi Akuntansi (JENIUS) 2: 261-77.

Sagarawanti, Nisrinna Dwi, and Wahyu Hidayat. 2015. "Pengaruh Kualitas Produk Dan Harga Terhadap Keputusan Pembelian Sepeda Motor." Jurnal Ekonomii 3 (2): 388-402.

Salawati, Trixie, and Rizki Amalia. 2010. "Perilaku Merokok Di Kalangan Mahasiswa Universitas Muhammadiyah Semarang." Prsiding Semnas.

Sugiyono. 2011. Metode Penelitian Kuantitatif, Kualitatif Dan $R \&$ D. Bandung: Alfabeta.

Sumardi, Mulyanto, and Hans Dieter Evers. 1991. Kemiskinan Dan Kebutuhan Pokok. Jakarta: CV Rajawali Citra Press.

Suprihanti, Antik, nFN Harianto, Bonar Marulitua Sinaga, and Reni Kustiari. 2019. "Dampak Kebijakan Cukai Rokok Terhadap Distribusi
Surplus Ekonomi Industri Rokok Di Indonesia." Jurnal Agro Ekonomi; Vol 37, No 1 (2019): Jurnal Agro Ekonomi. http://ejurnal.litbang.pertanian.go.id/index.php/jae /article/view/9584.

Suryawati, Chriswardani, Lucia Ratna Kartikawulan, and Ki Haryadi. 2012. "Konsumsi Rokok Rumah Tangga Miskin Di Indonesia Dan Penyusunan Agenda Kebijakannya." Jurnal Kebijakan Kesehatan Indonesia: JKKI; Vol 1, No 2 (2012). https://doi.org/10.22146/jkki.v1i2.35976.

Suyanto, and Nurhadi. 2003. IPS Ekonomi. Yogyakarta: Erlangga. 